\title{
Propuesta de difusión turística mediante herramientas web y estrategias de marketing digital. Caso de estudio: cantón Loja, Ecuador
}

\section{Tourist diffusion proposal, through web tools and digital marketing strategies. Case study: Loja canton, Ecuador}

María Fernanda Sotomayor Granda ${ }^{1}$

凶 Autor de correspondencia: mfsotomayor24@gmail.com

${ }^{\prime}$ Loja, Loja. 110150

Artículo original de la ponencia presentada en el IV CONGRETUR - "El impacto del turismo en el desarrollo del Ecuador", Universidad Central del Ecuador, 21 al 24 de noviembre de 2018

\begin{abstract}
Resumen
La intención de este estudio es la implementación de estrategias digitales para la promoción turística de destinos: Caso de estudio "El cantón Loja", partiendo de un diagnóstico turístico y observación web de campo. La metodología utilizada tiene dos enfoques: el cualitativo mediante entrevistas a profesionales en turismo de la localidad; y cuantitativo a través de encuestas realizadas de forma aleatoria a la planta turística, incluyendo un sondeo de opinión dirigido a turistas que visitan el cantón Loja. El estudio demostró las preferencias del turista al momento de investigar sobre el destino a visitar, y la existencia de una falta de innovación digital turística, en donde se pueda encontrar información real y confiable sobre el destino; además de la necesidad de contar con una página web oficial que pueda ofertar de mejor manera los atractivos turísticos del cantón Loja. Aún más, con los resultados obtenidos, se busca motivar a las empresas del sector y municipios sobre la importancia de la implementación de planes de marketing digitales que contribuyan al cumplimiento de objetivos de las campañas turísticas y competitividad en el mercado.
\end{abstract}

Palabras clave: Turismo, Competitividad, Promoción, Estrategias, Innovación.

\begin{abstract}
The purpose of this study is to propose the implementation of digital strategies for the promotion of tourist destinations: Case study " The Loja Canton" based on a tourist diagnosis and field web observation. The methodology used has two approaches; qualitative through interviews with local tourism professionals and quantitative through random surveys applied to of the tourist staff, including an opinion poll aimed at tourist visiting the Loja Canton. The study showed tourist's preferences when researching the destination to be visited and the existence of a lack of digital tourism innovation, in which real and reliable information about the destination can be found; in addition to the need for an official website that can offer in a better way the tourist attractions of the Loja Canton. Moreover, with the results obtained, we seek to motivate companies in this visiting sector and municipalities on the importance of implementing digital marketing plans, which contribute to meet the objectives of tourism campaigns and its competitiveness in the market.
\end{abstract}

Keywords: Tourism; Competitiveness; Promotion; Strategies; Innovation. 


\section{Introducción}

Para el sector turístico, "la introducción de las nuevas tecnologías ha generado beneficios y ha despertado la innovación en la industria y su estructura" (Flamarich, 2013). El uso de las tecnologías de la información y la comunicación en este sector ha incidido en decisiones estratégicas y sistemas de gestión de destinos. La Organización Mundial del Turismo [OMT] (2014) sostuvo que el uso de las nuevas tecnologías ha impulsado el interés de viajar $\mathrm{y}$ ha fomentado la comunicación de los consumidores y el fácil acceso de intercambio de información y experiencias. Además, las empresas se han podido adaptar a fórmulas de gestión, beneficiándose a través de sus herramientas digitales y elaborando procesos de comercialización. Con esto, promocionan sus productos a través de motores de búsqueda y páginas web, e interaccionan eficazmente con el consumidor, proporcionando servicios de información y multimedia como "Google Maps", "Google Earth", entre otros.

La nueva toma de decisiones del consumidor para elegir los lugares a visitar, es a través del internet y el fácil acceso a la información en cuanto a precio, características, horarios, servicios; lo que hace que se convierta en una búsqueda personalizada de acuerdo a gustos y preferencias. La búsqueda online representa el primer paso de los usuarios para programar un viaje. El turista adopta un rol de productor de contenidos, de autogestión de sus reservas, pueden visitar muchas páginas web en un solo día hasta lograr sus objetivos. Hoy en día las agencias de viajes que no tienen presencia online están de caída, mientras que las que deciden dar paso a las ventas por internet han mejorado su comercialización de productos y se han mantenido en el mercado. Michael Porter (economista, investigador y conferencista), entre sus aportes, destaca a "la cadena de valor" y a la "ventaja competitiva", como herramientas indispensables que toda empresa debe tener para poder sobresalir en el mercado y, sobre todo, por ser ese plus que permite al consumidor hacer su toma de decisiones. Por tanto, en un mundo globalizado y con tecnología de pasos agigantados, es imprescindible que el sector turístico sea innovador, adopte estrategias de comercialización y marketing ajustadas a un cliente más estricto, diferenciándose de la competencia.

\subsection{El marketing digital}

La evolución del marketing digital creció indudablemente en los últimos años. Este marketing digital introdujo nuevos conceptos como la comunicación
2.0, redes sociales, engagement marketing, branded communities, advertisement, blogs, posicionamiento SEO y SEM, marketing móvil, podcasting, remarketing, entre otros (Sotomayor, 2018). A diferencia del marketing tradicional, el marketing online ayudó a la expansión de las empresas hacia nuevos mercados tanto nacionales como internacionales, logrando llevar de manera simultánea la misma información a nivel mundial, permitiendo tener un número mayor de clientes potenciales, y la fidelización de clientes ya existentes (ZuiLi University, 2017). Habyb Selman (2017) en su libro Marketing digital lo definió como el conjunto de estrategias de mercadeo que ocurren en la web (en el mundo online) y que buscan algún tipo de conversión por parte del usuario.

El lema "la transformación digital" de la Organización Mundial del Turismo conmemorando el Día Mundial del Turismo 2018, fomentó la contribución al desarrollo del turismo sostenible, empoderamiento de comunidades locales, participación, inclusión y la eficacia que esta brinda para la gestión de recursos. Al marketing de destinos, no solo se lo ha considerado como una herramienta clave de atracción de visitantes, sino como un sistema eficiente y eficaz para el desarrollo turístico que delimita las estrategias de los mismos para que estos objetivos se cumplan (Bigné, Font y Andreu, 2000). Kotler et al. (2011), señalaron la existencia de tres principios básicos del marketing online: "Crear y gestionar eficazmente una base de datos de clientes; tener claro cómo puede la empresa sacar ventajas del internet; $y$, tener acceso rápido y respuesta rápida en el servicio al cliente".

\subsection{Justificación}

Esta investigación realizada en el año 2016, se enfocó en la presencia online y digital del cantón Loja como destino turístico; partiendo de una observación de campo acerca de la existencia de servicios y herramientas web, lo que permitió identificar ciertas desventajas en cuanto a su difusión turística. Uno de los resultados fue el no contar con una plataforma web oficial de turismo administrado por una entidad gubernamental, además, cierta información encontrada en los buscadores no es del todo fidedigna. Adicionalmente se aportó con la implementación de estrategias de marketing digital, que en su momento se pueden aplicar para ir midiendo resultados paulatinamente.

En el Ecuador, algunas ciudades como Guayaquil, Quito y Cuenca, optaron por el uso de herramientas digitales mediante el empleo de portales web apoyados mediante estrategias en redes 
sociales, promocionando a sus ciudades conjuntamente con su oferta turística. Entre las páginas oficiales que se pueden nombrar están: Quito Turismo, Guayaquil es mi Destino y Fundación Municipal Turismo de Cuenca; que como resultado se han convertido en ciudades más competitivas local e internacionalmente.

El cantón Loja, cuenta con magníficos atractivos turísticos naturales y culturales, así como una excelente planta turística dispuestos a ser ofertados a los visitantes; sin embargo, su promoción se ha mantenido utilizando estrategias offline con muy poco uso de los alcances digitales de hoy en día. Según el Plan de Ordenamiento Turístico Zonal 7 [PDOT] (s.f. p. 16) un $62 \%$ de los turistas no contrataron ningún servicio turístico ofertado en la zona, debido a un desconocimiento, altos costos y poco interés por parte de los turistas. Por otra parte, la provincia de Loja fue considerada como la provincia con mayor visita de turistas entre la región de planificación zonal 7 (El Oro, Loja, Zamora) con un $65 \%$; la mayor concentración de turismo se registró en el cantón Loja (PDOT de Loja, 20142022). Además, los motivos de visita fueron por turismo religioso, turismo cultural, ecoturismo, turismo de salud y turismo de convenciones; los sitios elegidos por los turistas se centraron mayormente en este cantón, ubicando a Vilcabamba en el primer lugar entre sus opciones, seguido por la ciudad de Loja y sus alrededores.

Se añade a esta información, un análisis de la estructura del sistema turístico del cantón Loja basado en el "modelo del sistema turístico", escrito por Roberto Boullón (2004), en donde explica que el modelo mencionado "es la suma de los bienes solicitados por los consumidores y que esta oferta turística está integrada por los servicios pertenecientes a la planta turística y bienes no turísticos, regulados por las instituciones que conforman la superestructura del mismo". Por tal motivo se desarrolló un levantamiento de información de los recursos con los que cuenta el cantón Loja: planta turística, atractivos turísticos (naturales y culturales) y eventos o manifestaciones programadas que enmarca a festividades y eventos de carácter cultural y patrimonial.

Es indispensable que el ente gubernamental que va a administrar los medios web se apoye en el marketing digital empezando por el diseño de una plataforma web para que los turistas tengan acceso a toda la información necesaria de primera mano y esta sea de fuentes confiables, además, es una herramienta clave para poder posicionar una marca ciudad y todos los recursos que se puedan ofrecer al visitante y a la vista del mundo de forma online.

\section{Materiales y métodos}

Para el desarrollo de la investigación se aplicaron dos tipos de enfoque:

1. El enfoque cualitativo, el cual, de acuerdo con Hernández et al. (2006) pretende clarificar preguntas en el proceso de interpretación, sin utilizar mediciones de carácter numérico. Según Bonilla \& Rodríguez (2000), en Bernal (2010), este método está orientado a cualificar y describir un fenómeno social a partir de rasgos determinantes dentro de una situación estudiada. Uno de los objetivos principales del método cualitativo es acaparar datos más reales sobre un tema específico. Por tanto, se realizó entrevistas a expertos, mediante la recopilación de información de los diferentes puntos de vista sobre la funcionalidad de la propuesta, enfocado en la gestión turística del destino; y una entrevista dirigida a un experto en marketing digital para el planteamiento de estrategias.

2. Aplicación del enfoque cuantitativo, a través de encuestas, que es uno de los instrumentos más utilizados en la recolección de datos, y que está fundamentado en un conjunto de preguntas con diversas variables (Hernández, Fernández y Baptista, 2006). La encuesta fue de tipo aleatoria simple dirigida al sector de servicios turísticos del cantón Loja.

Y para finalizar la investigación, se realizó un sondeo de opinión a turistas que estaban de visita en el cantón Loja, debido a que no se encontraron datos estadísticos oficiales en cuanto al número de visitantes que llegaron a este cantón.

\subsection{Técnicas e instrumentos de investigación}

A continuación, se muestra en la tabla 1 la clasificación de los instrumentos aplicados para cada fase de la investigación. 
Tabla 1. Instrumentos de investigación

\begin{tabular}{|c|c|c|}
\hline Productos & Elemento que valora & Instrumentos aplicados \\
\hline \multirow{2}{*}{ Inventario de atractivos turísticos } & $\begin{array}{l}\text { Identificación de atractivos } \\
\text { potenciales. }\end{array}$ & \multirow{2}{*}{$\begin{array}{l}\text { Ficha de atractivos turísticos } \\
\text { MINTUR. }\end{array}$} \\
\hline & $\begin{array}{l}\text { Análisis de los atractivos } \\
\text { potenciales. }\end{array}$ & \\
\hline \multirow[b]{2}{*}{ Planta turística } & Identificación de establecimientos & \multirow{2}{*}{$\begin{array}{l}\text { Análisis del último catastro de } \\
\text { establecimientos turísticos del } \\
\text { cantón Loja. }\end{array}$} \\
\hline & $\begin{array}{l}\text { Análisis y procesamiento de } \\
\text { información. }\end{array}$ & \\
\hline Análisis de la demanda & $\begin{array}{l}\text { Identificación de la demanda y } \\
\text { perfil del visitante. }\end{array}$ & $\begin{array}{l}\text { - Entrevista aplicada a experto } \\
\text { en turismo: ITUR- Municipio } \\
\text { de Loja. } \\
\text { - Estadísticas oficiales MINTUR } \\
\text { e INEC. }\end{array}$ \\
\hline \multirow{4}{*}{ Diseño del medio web } & Recopilación del contenido web. & \multirow{4}{*}{$\begin{array}{l}\text { Entrevistas estructuradas } \\
\text { dirigidas a representantes de } \\
\text { instituciones turísticas del } \\
\text { cantón Loja y a experto en } \\
\text { marketing digital } \\
\text { - Encuestas al sector turístico y } \\
\text { sondeo de opinión a turistas } \\
\text { - Visita a diseñador web }\end{array}$} \\
\hline & Diseño estructural web. & \\
\hline & Costeo de la página web. & \\
\hline & Puesta en marcha de la página web. & \\
\hline
\end{tabular}

\subsubsection{Entrevistas}

Para Kvale (2011), las entrevistas son uno de los principales métodos de recolección de datos dentro del enfoque cualitativo. En ellas se intercambian ideas mediante un cuestionario minucioso entre el entrevistador y entrevistado con el propósito de abordar temas de interés. Para poder diseñar las en- trevistas, se dividió en tres partes: una primera entrevista enfocada en el perfil del turista que ha visitado el cantón Loja; un segundo tipo de entrevista enfocado en las necesidades de información que requiere el portal web como herramienta de promoción turística, y una última enfocada en marketing digital. Y se realizó un esquema de entrevistas (Tabla 2).

Tabla 2. Esquema de entrevistas

\begin{tabular}{lcc}
\multicolumn{1}{c}{ Tipo de entrevista } & Nombre del informante & Institución a la que pertenece \\
\hline $\begin{array}{l}\text { Entrevista perfil del turista/ } \\
\text { Entrevista medios web }\end{array}$ & Ing. Diego Castro & Itur - Municipio de Loja \\
\hline Entrevista medios web & Marco García & Ministerio de Turismo \\
\hline Entrevista medios web & Karla León & GAD parroquial Vilcabamba \\
\hline Entrevista medios web & Lic. Jorge Veintimilla & CAPTUR Loja \\
\hline Entrevista marketing digital & Dr. Fernando Checa & Universidad Internacional de La Rioja
\end{tabular}

\subsubsection{Encuestas}

La encuesta es un método de investigación que permite la obtención de información a través de fuentes primarias. Aún más, Trespalacios,
Vázquez y Bello (2005), argumentaron que las encuestas precisan la identificación de las preguntas a realizar a través de una muestra representativa de población y especificando respuestas. La encuesta se la realizó al sector de servicios turísticos (planta 
turística), el cual tiene un total de 225 establecimientos, dando una muestra de 144 encuestas; de modo que se realizó una (1) encuesta por establecimiento. El enfoque de la encuesta fue sobre la acep- tación de los medios web para la difusión turística del cantón Loja y, además, se realizaron preguntas sobre su estructura y necesidades de información para la misma.

$$
n=\frac{N}{E^{2}(N-1)+1}
$$

Donde,

$\mathrm{n}=$ muestra

$\mathrm{N}=$ población $=225$ establecimientos

$\mathrm{E}=$ error $=5 \%$

Reemplazando los valores en la ecuación,

$$
\begin{gathered}
n=\frac{225}{0,05^{2} *(225-1)+1} \\
n=144.23 \text { encuestas }
\end{gathered}
$$

\subsubsection{Sondeo de opinión}

Es una forma de medición estadística destinado a conocer la opinión pública (Ojeda y Gontero, 2010). El sondeo de opinión fue realizada a turistas en el cantón Loja, cuya finalidad fue conocer a través de qué medios obtuvieron información turística del cantón y qué tipo de información les gustaría encontrar en la propuesta.

\subsubsection{Proceso de levantamiento de información}

Como primer punto, se definió en qué entorno se realizaría la investigación de campo y qué instrumentos se iban a necesitar para lograr los objetivos (Figura 1). Luego, se delimitó el área de estudio, lo cual permitió no extenderse más allá de los límites necesarios para realizar la investigación. En el caso de este proyecto se delimitó desde Loja (provincial) a Loja (cantonal). La revisión de documentos basado en libros, folletos turísticos emitidos por las diferentes entidades, catastros, boletines estadísticos, planes de desarrollo, proyectos académicos entre otros. La planificación del proyecto se centró en aspectos fundamentales: el recurso humano: actores involucrados y profesionales en el campo; la metodología: de carácter cualitativa, lo que implicó las diferentes entrevistas y cuantitativa que involucró encuestas y sondeos de opinión. Los materiales: los necesarios para la recopilación de información como computadoras, cámaras fotográficas, grabadora de voz; y los limitantes de estudio tomando en cuenta al tiempo y posibles fuentes de información no académicas u oficiales.

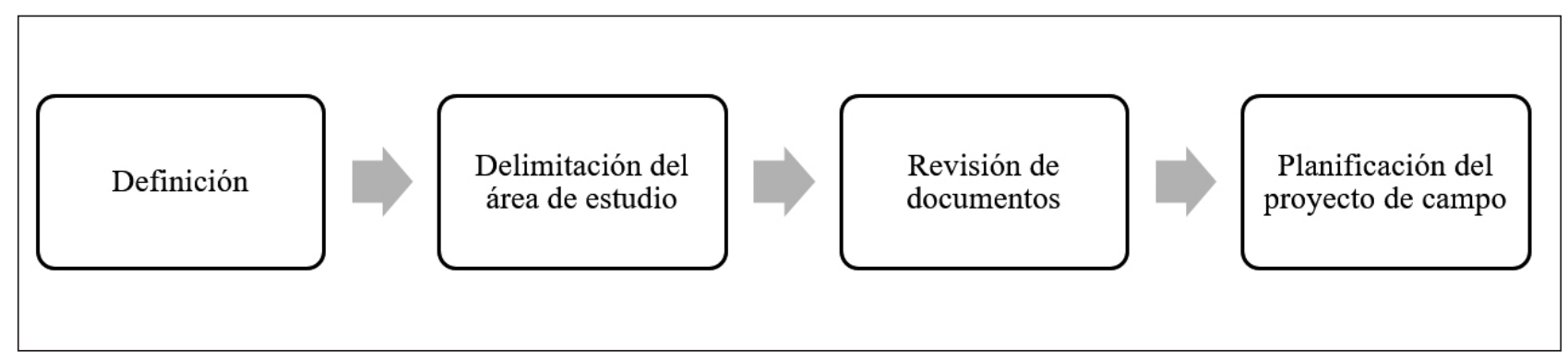

Figura 1. Procedimiento para el levantamiento de información. 


\section{Resultados y discusión}

A continuación, se exponen los resultados obtelucrados en base a la estructura de un sitio web como nidos en las entrevistas realizadas a los actores invoherramienta de promoción turística del cantón Loja.

Tabla 3. Resultados de las entrevistas a los actores locales involucrados

\begin{tabular}{|c|c|c|c|c|}
\hline Preguntas & GAD Loja & Mintur & $\begin{array}{c}\text { GAD } \\
\text { parroquial }\end{array}$ & CAPTI \\
\hline $\begin{array}{l}\text { 1. ¿Considera } \\
\text { importante } \\
\text { el desarrollar } \\
\text { una platafor- } \\
\text { ma web, para } \\
\text { la difusión } \\
\text { del potencial } \\
\text { turístico de } \\
\text { Loja? }\end{array}$ & $\begin{array}{c}\text { Muy } \\
\text { importante }\end{array}$ & $\begin{array}{c}\text { Súper } \\
\text { importante }\end{array}$ & $\mathrm{Si}$ & $\mathrm{Si}$ \\
\hline
\end{tabular}

\begin{tabular}{|c|c|c|c|c|}
\hline $\begin{array}{l}\text { 2. ¿Qué tipo } \\
\text { de información } \\
\text { creo que se } \\
\text { debería mostrar } \\
\text { en este sitio? }\end{array}$ & $\begin{array}{l}\text { - Información } \\
\text { general. } \\
\text { - Orientación al } \\
\text { turista. }\end{array}$ & $\begin{array}{l}\text { - Destinos } \\
\text { - Atractivos } \\
\text { turísticos }\end{array}$ & $\begin{array}{c}\text { - Servicios } \\
\text { - Facilidades }\end{array}$ & $\begin{array}{l}\text { - Atractivos } \\
\text { turísticos. } \\
\text { - Alojamiento } \\
\text {-Gastronomía }\end{array}$ \\
\hline $\begin{array}{l}\text { 3. ¿Cree usted } \\
\text { que este sitio } \\
\text { debe estar in- } \\
\text { tegrado a redes } \\
\text { sociales? }\end{array}$ & Son esenciales & $\mathrm{Si}$ & $\mathrm{Si}$ & $\mathrm{Si}$ \\
\hline $\begin{array}{l}\text { 4. ¿Qué redes } \\
\text { sociales? }\end{array}$ & $\begin{array}{l}\text { - Twitter } \\
\text { - Facebook }\end{array}$ & $\begin{array}{l}\text { - Facebook. } \\
\text { - Twitter } \\
\text { - Instagram }\end{array}$ & $\begin{array}{l}\text { - Facebook } \\
\text { - Twitter } \\
\text { - Instagram }\end{array}$ & $\begin{array}{l}\text {-Facebook } \\
\text { - Twitter } \\
\text { - Instagram }\end{array}$ \\
\hline $\begin{array}{l}\text { 5. Desde su } \\
\text { institución que } \\
\text { información } \\
\text { cree que sea } \\
\text { relevante actu- } \\
\text { alizar constan- } \\
\text { temente. }\end{array}$ & $\begin{array}{l}\text { - Prestación } \\
\text { de servicios } \\
\text { turísticos. } \\
\text { - Eventos del } \\
\text { año. }\end{array}$ & $\begin{array}{c}\text { - Noticias } \\
\text { - Eventos } \\
\text { - Inclusión de } \\
\text { nuevos lugares } \\
\text { y destinos }\end{array}$ & $\begin{array}{c}\text { - Actividades } \\
\text { - Fiestas parro- } \\
\text { quiales }\end{array}$ & $\begin{array}{c}\text { - Trabajos } \\
\text { con el sector } \\
\text { privado }\end{array}$ \\
\hline $\begin{array}{l}\text { 6. ¿Qué otras } \\
\text { herramientas } \\
\text { electrónicas } \\
\text { cree usted que } \\
\text { deben acom- } \\
\text { pañar a una } \\
\text { plataforma web } \\
\text { para la correcta } \\
\text { difusión del } \\
\text { mismo'? }\end{array}$ & $\begin{array}{l}\text { - Asesoría en } \\
\text { tiempo real. } \\
\text { - Enlaces con } \\
\text { comentarios } \\
\text { - Mapas Geolo- } \\
\text { calización } \\
\text { - Directorio de } \\
\text { planta turística } \\
\text { con links }\end{array}$ & $\begin{array}{l}\text { Blog de in- } \\
\text { formación y } \\
\text { noticias. }\end{array}$ & Redes sociales & - Mapas \\
\hline
\end{tabular}




\begin{tabular}{|c|c|c|c|c|}
\hline $\begin{array}{l}\text { 7. ¿Cómo cree } \\
\text { que deberá ser } \\
\text { la estructura } \\
\text { física? }\end{array}$ & $\begin{array}{l}\text { - Muy simple y } \\
\text { viable. } \\
\text { - Lenguaje } \\
\text { coloquial. } \\
\text { - Amigable con } \\
\text { el turista. }\end{array}$ & $\begin{array}{l}\text { Responsable y } \\
\text { atractiva. } \\
\text { - Que se pueda } \\
\text { usar en tablets } \\
\text { y dispositivos } \\
\text { móviles. }\end{array}$ & $\begin{array}{c}\text { - Íconos } \\
\text { grandes. } \\
\text { - Texto general. }\end{array}$ & $\begin{array}{l}\text { Visualmente } \\
\text { atractiva, con } \\
\text { fotografías y } \\
\text { videos }\end{array}$ \\
\hline $\begin{array}{c}\text { 8. ¿Conoce } \\
\text { algún ejemplo } \\
\text { de plataforma } \\
\text { web? }\end{array}$ & $\begin{array}{l}\text { No tiene un } \\
\text { ejemplo a } \\
\text { seguir, la cre- } \\
\text { atividad, ante } \\
\text { todo. }\end{array}$ & Ecuador Travel & $\begin{array}{c}\text { Ecuador ama la } \\
\text { vida }\end{array}$ & $\begin{array}{l}\text { Fundación } \\
\text { Turismo de } \\
\text { Cuenca }\end{array}$ \\
\hline $\begin{array}{l}\text { 9. ¿Cómo in- } \\
\text { stitución como } \\
\text { les gustaría } \\
\text { involucrarse en } \\
\text { el desarrollo y } \\
\text { ejecución de } \\
\text { este medio? }\end{array}$ & $\begin{array}{l}\text { Por supuesto, } \\
\text { incluso está } \\
\text { dentro de los } \\
\text { planes } 2016 .\end{array}$ & $\begin{array}{l}\text { Sí, apoyando } \\
\text { en todo lo } \\
\text { necesario para } \\
\text { su desarrollo. }\end{array}$ & $\begin{array}{l}\text { Como medio } \\
\text { de difusión } \\
\text { parroquial }\end{array}$ & $\begin{array}{l}\text { Siendo inclu- } \\
\text { yentes con } \\
\text { información }\end{array}$ \\
\hline
\end{tabular}

Según los resultados de la tabla 3 , se recomendó que la propuesta de una plataforma web:

- Sea de fácil comprensión para el usuario, es decir, evitar lenguajes y léxicos complejos, que el contenido sea claro y específico.

- El uso de las redes sociales como: Facebook, Twitter e Instagram.

- $\quad$ El medio web debe ser apto para usarse en $t a-$ blets, y smatphones.

- Visualmente debe contener fotografías y videos sobre la oferta turística.

- Incluir una sección de eventos y noticias de interés, que se puedan actualizar constantemente.

- Algunas páginas de ejemplo que los entrevistados consideran son: "Ecuador Travel", "Ecuador ama la vida" y "Fundación Turismo de Cuenca".

- Los entrevistados expresan que están de acuerdo en apoyar e involucrarse con el proyecto, brindando la información necesaria en cuanto les sea posible.

\subsection{Resultados de la encuesta realizada al sector de servicios turísticos.}

En la figura 2 se observa que la mayor parte de las personas que laboran en los establecimientos tu- rísticos han hecho uso del internet como medio de búsqueda de información turística. Además, sabían sobre el uso de herramientas web para promocionar destinos turísticos, pero en su caso no los han aplicado mucho (Figura 3). Los encuestados consideraron que la promoción turística que se le ha dado al cantón Loja es escasa (Figura 4), y un $85 \%$ aseguró no encontrar una página web especializada en información turística; solamente la página oficial municipal (http://www. loja.gob.ec) cuya información es general; un 15\% aseguró haber conocido de páginas web con información sobre el cantón Loja, sin embargo, contenían pocos datos y presentaban resultados no muy confiables, sin enfoque exclusivamente en Loja (Figura 5).

La mayoría de los encuestados consideraron importante el promover el turismo a través de los medios web, como se observa en la figura 6 , y varias de sus razones fueron que en la actualidad el turista realiza la búsqueda de destinos en portales web y que planifica sus viajes de acuerdo a la información obtenida. Para los encuestados, los medios web que serían aptos para promocionar turismo son de preferencia en la creación de una página web y el uso de las redes sociales, seguido de blogs y con un $5 \%$ información vía correo electrónico y aplicaciones móviles. Por otra parte, la figura 7 muestra la aceptabilidad de los encuestados por un medio web de información turística oficial para el cantón Loja. Solamente una persona respondió que no le gustaría y su justificación fue debido a que no quisiera que el Municipio de Loja la administre.

Finalmente, eligieron algunas herramientas que deberían considerarse en el diseño de la página web 
propuesta, como mapas de ubicación, idiomas, botones de búsqueda de información, links de enlace di- recto a páginas de la planta turística y redes sociales (Figura 9).

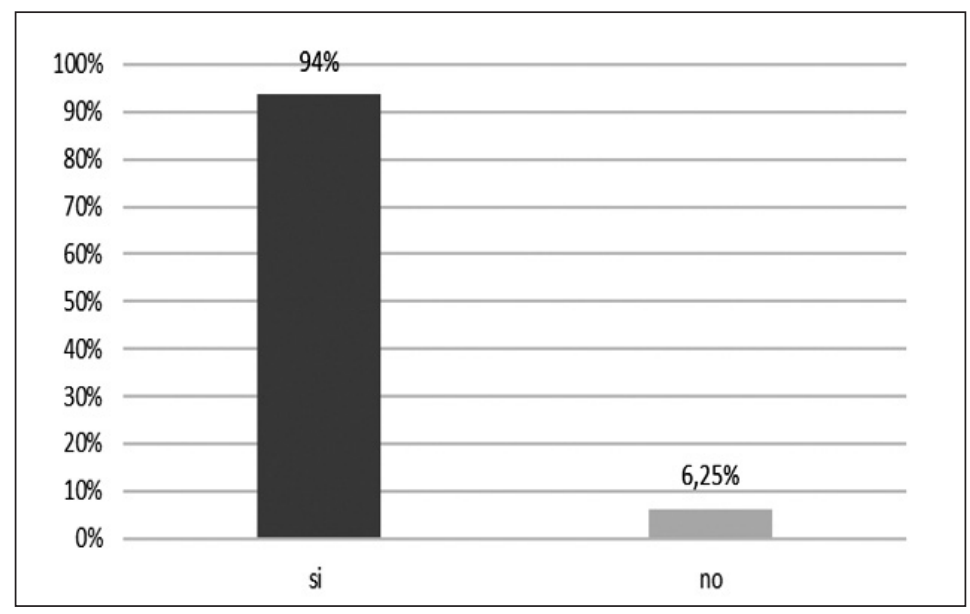

Figura 2. Uso de internet para información turística.

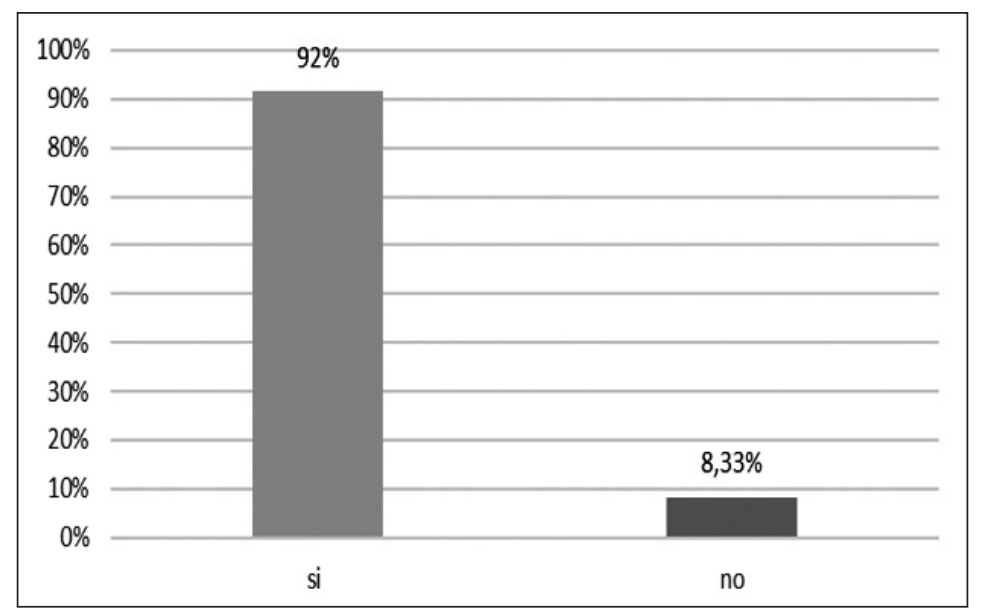

Figura 3. Uso de medios web para promoción turística.

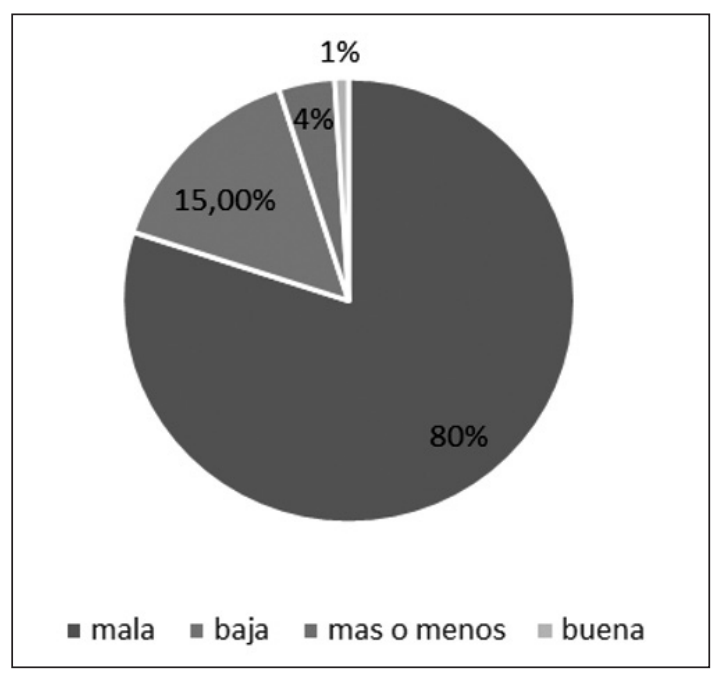

Figura 4. Promoción turística del cantón Loja. 


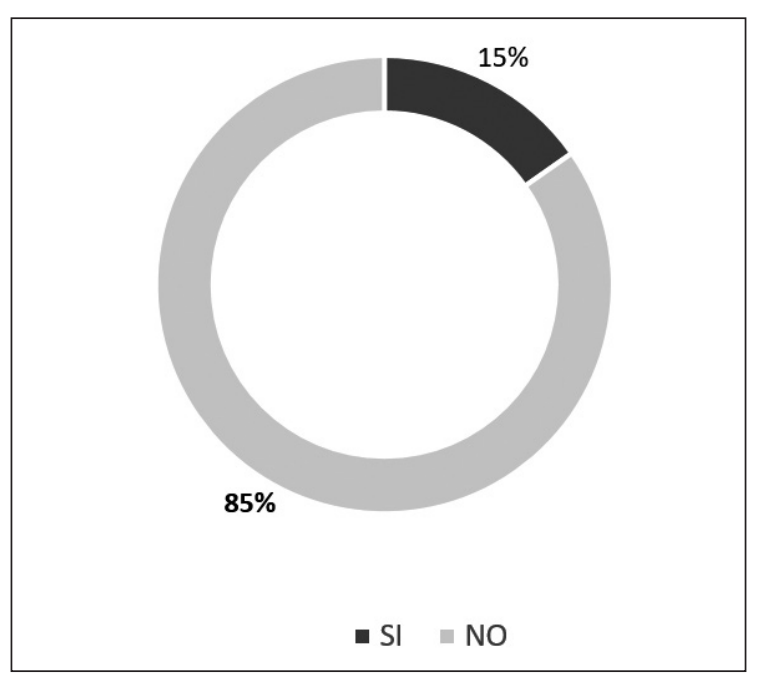

Figura 5. Existencia de una página web oficial de turismo.

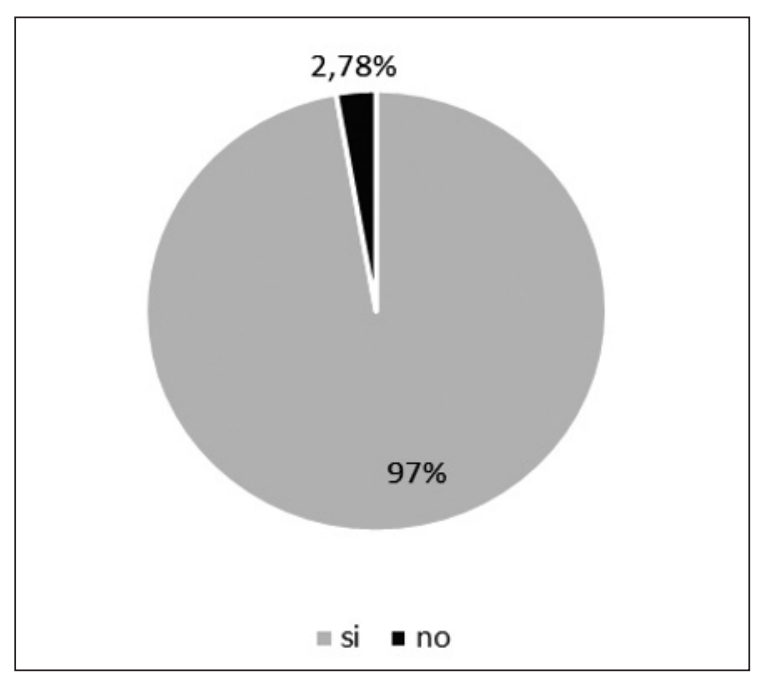

Figura 6. Importancia de promover turismo por medios Web.

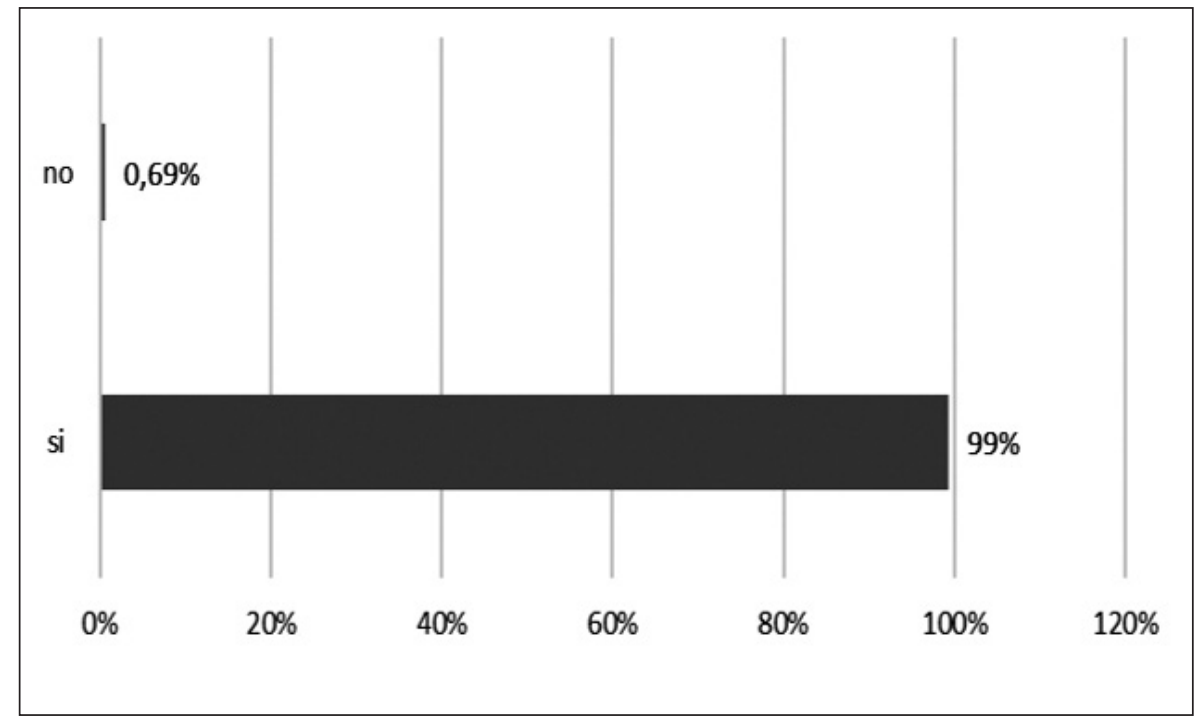

Figura 7. Aceptabilidad de una página web para el cantón Loja. 


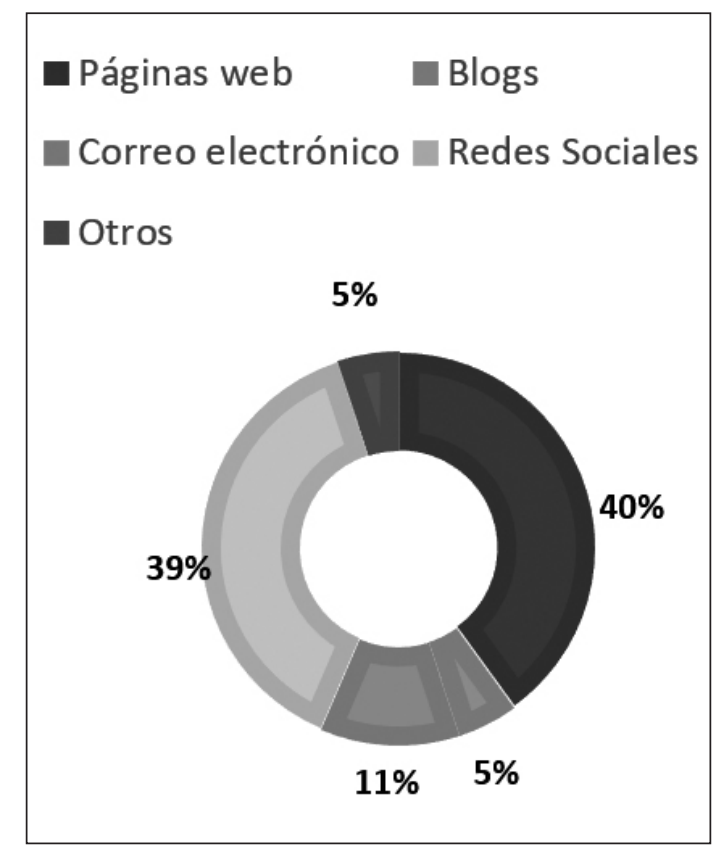

Figura 8. Medios web elegidos por los encuestados.

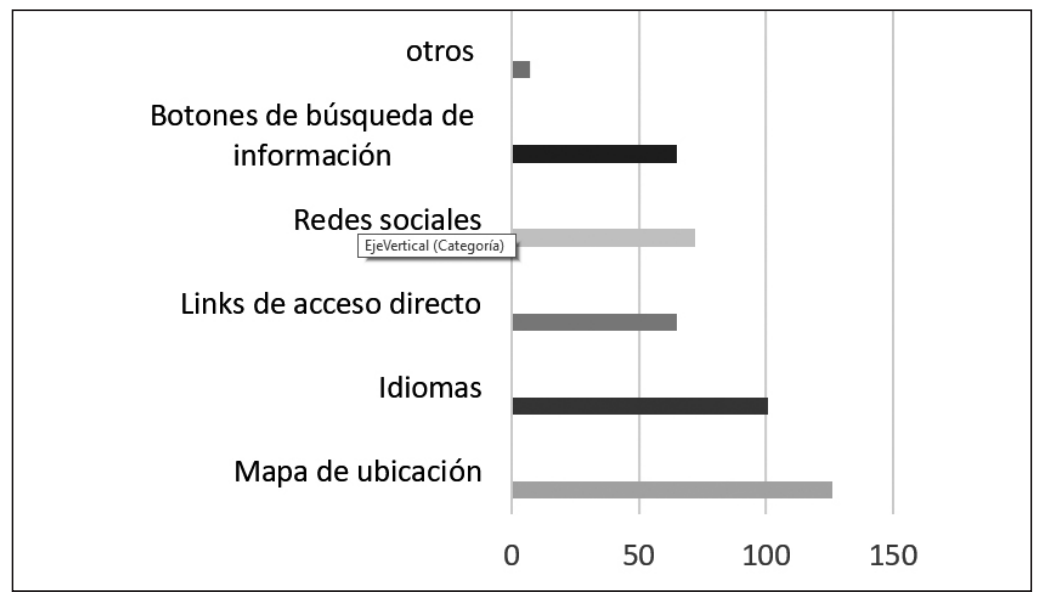

Figura 9. Herramientas que se deberían encontrar en un sitio web.

\subsection{Resultados del sondeo de opinión, realizado a turistas que visitan el cantón Loja.}

Los siguientes son los resultados de un sondeo de opinión realizado a 20 turistas aleatoriamente en el valle de Vilcabamba del cantón Loja. Se determinó que la mayoría de turistas encuestados hicieron uso de internet para la obtención de información turística de Loja y consideraron importante y necesario promover destinos turísticos a través del internet (medios digitales) (figuras 10 y 11). Los turistas expresaron haber organizado su viaje sin la ayuda de una agencia de viajes, es decir, lo autogestionaron por su cuenta, tal como lo muestra la figura 11 y desconocen la existencia de una plataforma web oficial. Como un dato importante y que debería ser considerado, es que en un principio su idea de viaje fue conocer solamente Vilcabamba, creyendo que era un destino totalmente independiente de Loja, además, opinaron que es un lugar que se vende solo. En la figura 13 se observa los motivos de visita al cantón Loja: un $41 \%$ respondió que fue por vacaciones, un $32 \%$ por turismo de salud, un $14 \%$ por negocios, y un 13\% porque visitaron amigos y planificaban radicarse en Vilcabamba. También, 11 turistas obtuvieron información mediante internet, algunos de ellos responden haberla encontrado en OTAS (Online Travel Agencies" o "Agencias de viaje en línea") como Booking.com y Expedia.com; y 9 turistas respondieron que fue por recomendación de otra persona (boca a boca) y sugerencias de viajeros (Figura 12). 


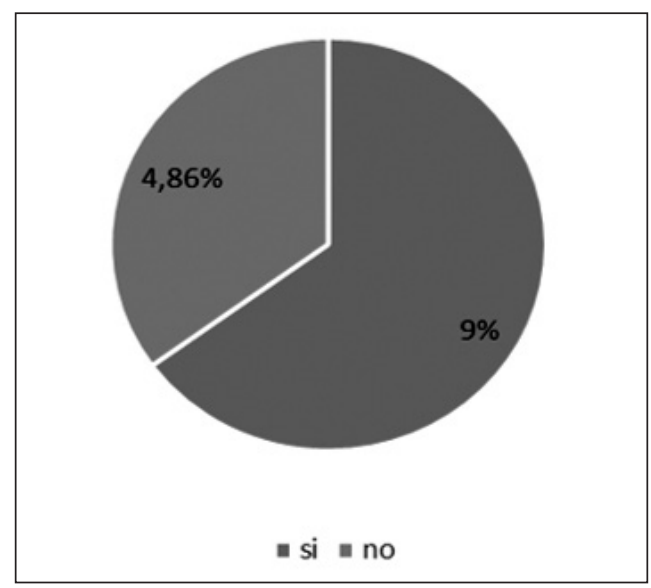

Figura 10. Personas que usan internet como fuente Información turística.

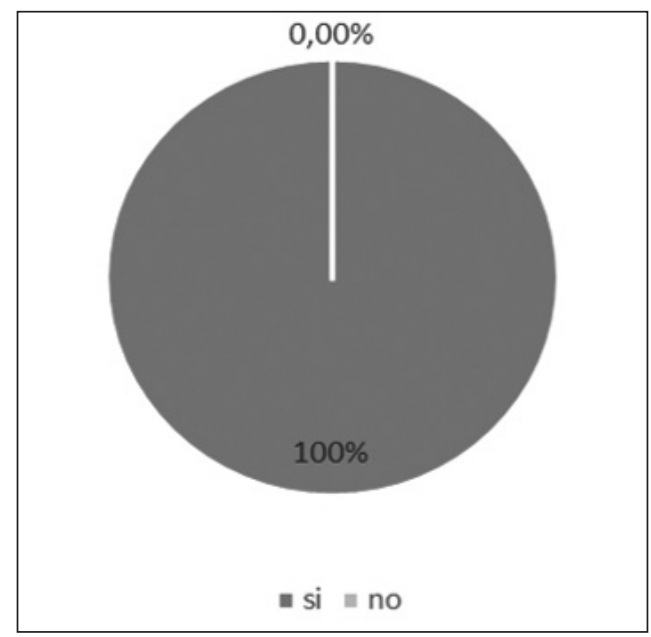

Figura 11. Consideran importante a los medios web en el turismo.

En este sondeo de opinión, los turistas aclararon que les fue difícil encontrar información necesaria como estaciones de transporte turístico, mapas, información sobre dónde pernotar (hospedaje), hotelería, restaurantes, distancias entre pueblos y hasta incluso la búsqueda de centros de salud cercanos. Como aporte, recomendaron que se incluyan las he- rramientas necesarias en una página web turística, sobre todo para encontrar fácilmente la información; también mencionaron el acceso a contenido en redes sociales, botones de búsqueda, idiomas, secciones en donde se encuentre información de alojamiento, restaurantes, transporte y que se pueda visualizar eficazmente desde el teléfono móvil.

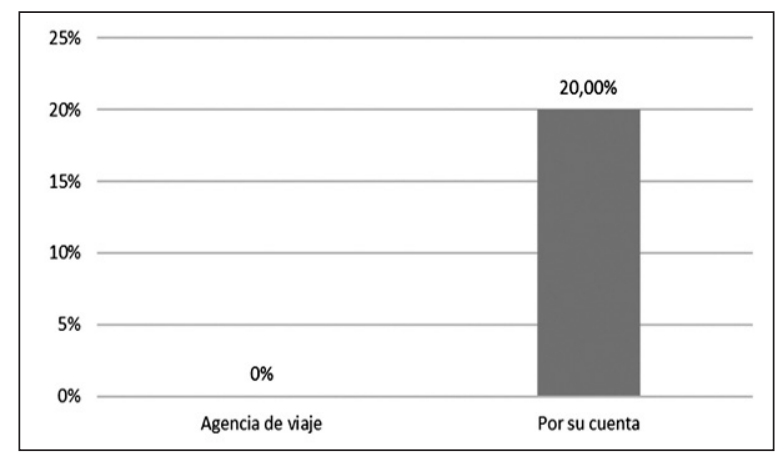

Figura 12. Forma de organizar el viaje. 


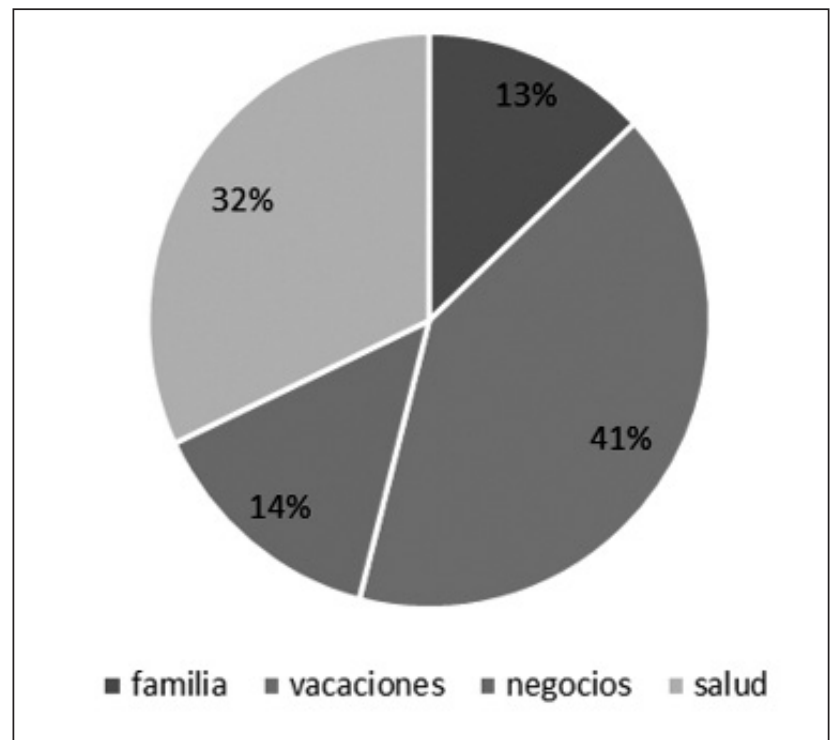

Figura 13. Motivos de visita al cantón Loja.

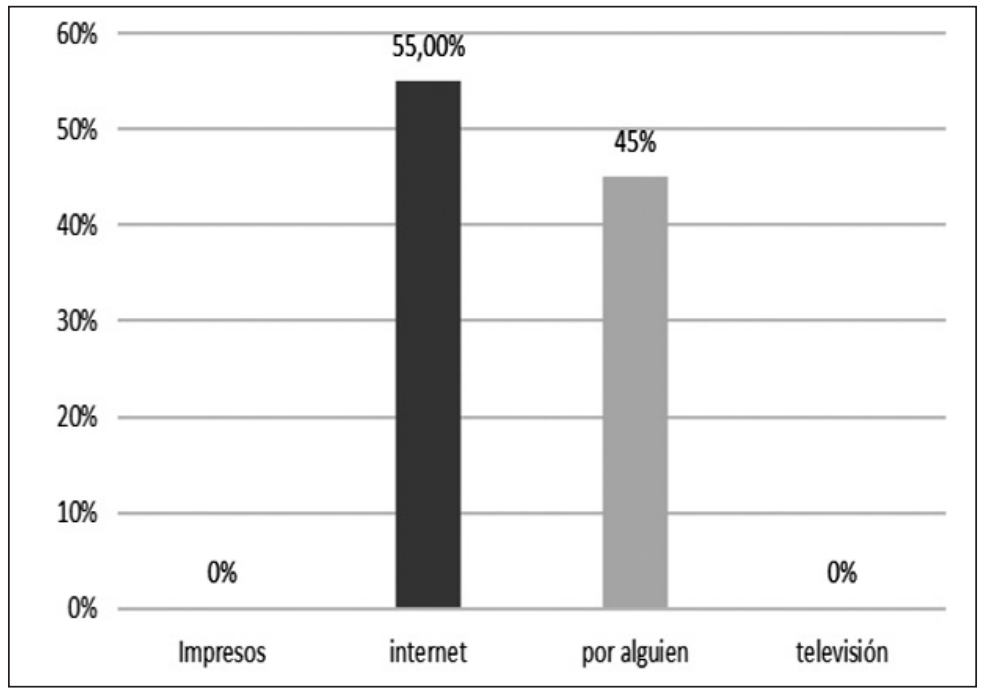

Figura 14. Medios por el que obtuvieron información.

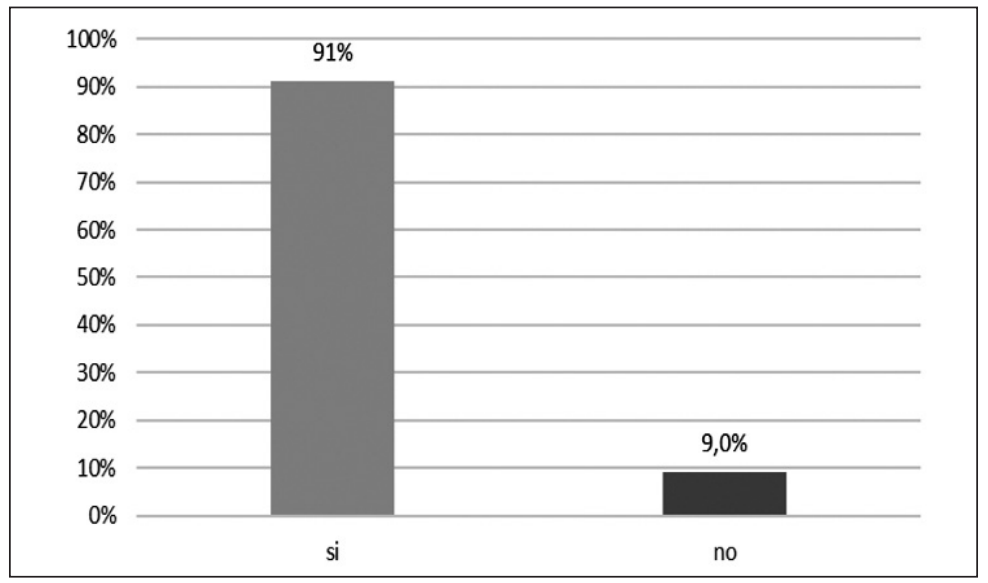

Figura 15. Porcentaje de encuestados que saben de la existencia de un medio web oficial. 


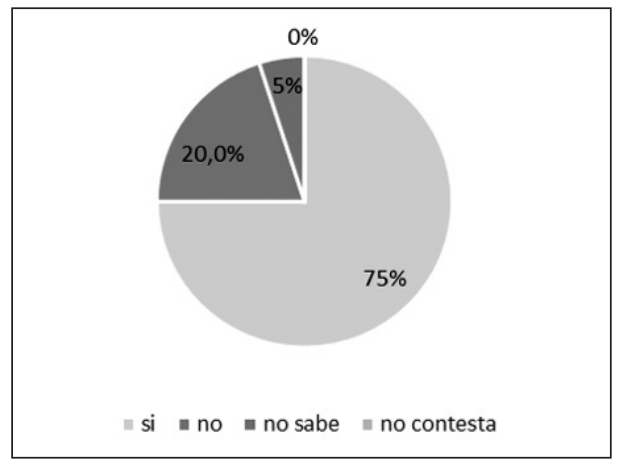

Figura 16. Personas que están de acuerdo en el uso de un medio web para promoción turística.

\subsection{Estrategias de marketing digital}

Se considera que es necesario contar con una plataforma web y redes sociales con información turística, recalcando una vez más que una página web forma parte del marketing digital, y que es una de las herramientas base para poder tener éxito en los objetivos de marketing que se quieren cumplir en el presente caso. Para Fernando Checa (profesor, investigador y experto en marketing digital y social media, autor de más de 20 publicaciones especializadas en España), es imprescindible contar con una página web, sobre todo si entre los objetivos está el posicionamiento de la marca de un producto o servicio mediante internet. Un plan de marketing digital debe trazar objetivos, con estrategias y tácticas para poder alcanzarlos.

Algunos objetivos en marketing digital son: generar tráfico, obtener seguidores, aumentar las ventas, ganar posicionamiento en el mercado. Además, un plan de marketing digital comienza con un análisis del entorno interno del sitio web: análisis de las redes sociales que se usan, ¿Cómo se encuentra la empresa en cuanto a posicionamiento en los buscadores; $i \mathrm{el}$ contenido que se publica da resultados?, planificación estratégica y calendarios. También se realiza un análisis de situación externo ¿Cuál es el target?, ¿Público objetivo?, ¿Segmento de mercado?, ¿Quiénes son los competidores?; y sumado a esto medir los resultados y generar un plan de acción.

El uso de social media también forma parte del marketing digital y a su vez también comprende sub-objetivos y una planificación a ser realizados para cada red social. Checa (2018) en su entrevista, sugirió definir cada uno de los objetivos digitales que son diferentes a los objetivos generales corporativos y que deben ser SMART (específicos, medibles, alcanzables, relevantes y temporales). En la tabla 4, se puede comprender con claridad el uso de las estrategias y tácticas para cada objetivo propuesto. Además, recomendó actualizar los contenidos, refrescar la información y estar siempre a la vanguardia para evitar que los usuarios abandonen el sitio web, para que así el tiempo de permanencia de los usuarios aumente, que se puedan convertir en visitantes potenciales, interactivos, y que compartan la información. A continuación, se han expuesto estrategias y tácticas elegidas para el caso en la tabla 4.

Tabla 4. Algunos ejemplos de estrategias y tácticas de marketing digital.

Objetivo

\begin{tabular}{ll}
\hline Posicionamiento web & $\begin{array}{l}\text { Uso de palabras claves } \\
\text { SEO y SEM. }\end{array}$ \\
\hline $\begin{array}{l}\text { Generar leads (clientes, visitantes } \\
\text { potenciales) }\end{array}$ & $\begin{array}{l}\text { Diseñar una página de aterrizaje que lleve a los } \\
\text { visitantes a suscribirse para recibir información. }\end{array}$
\end{tabular}

Reducir los abandonos de página.

Hacer que la experiencia del usuario sea de calidad, tanto en usabilidad como tiempo de carga, optimización web y optimización móvil.

Tener presencia en redes sociales como canal de

Notoriedad de la página YouTube, Facebook, Twitter, Instagram.
Táctica

Ir actualizándolo en contenido, artículos turísticos y educativos. Elección de palabras claves correctas.

A cambio, permitirles el acceso a libros gratuitos online, boletines informativos turísticos y regalos acorde.

Realizar análisis sobre el tiempo de permanencia del usuario, motivos de búsqueda de información. Mantenimiento.

Generar contenido netamente de interés turístico, educativo, informativo, noticias turísticas actualizadas. 
A continuación, algunos indicadores para medir resultados descritos en la siguiente tabla.

Tabla 5. Algunos ejemplos de indicadores de medición de resultados en marketing digital.

Indicadores

Número de sesiones totales

Usuarios que visitan la página

Número de páginas visitadas

Sitio web y blog

Número de páginas vistas por sesión

Número de conversiones leads

Fuentes de conversiones leads

Sesiones por redes sociales, dispositivos, campañas

Tiempo de permanencia promedio por tipo de usuario

Tráfico orgánico

Porcentaje de conversiones por canales de tráfico

Informe de posicionamiento SEO

Páginas con mayor número de conversiones

Páginas más visitadas y tiempo de permanencia

Sesiones por búsqueda de palabras clave

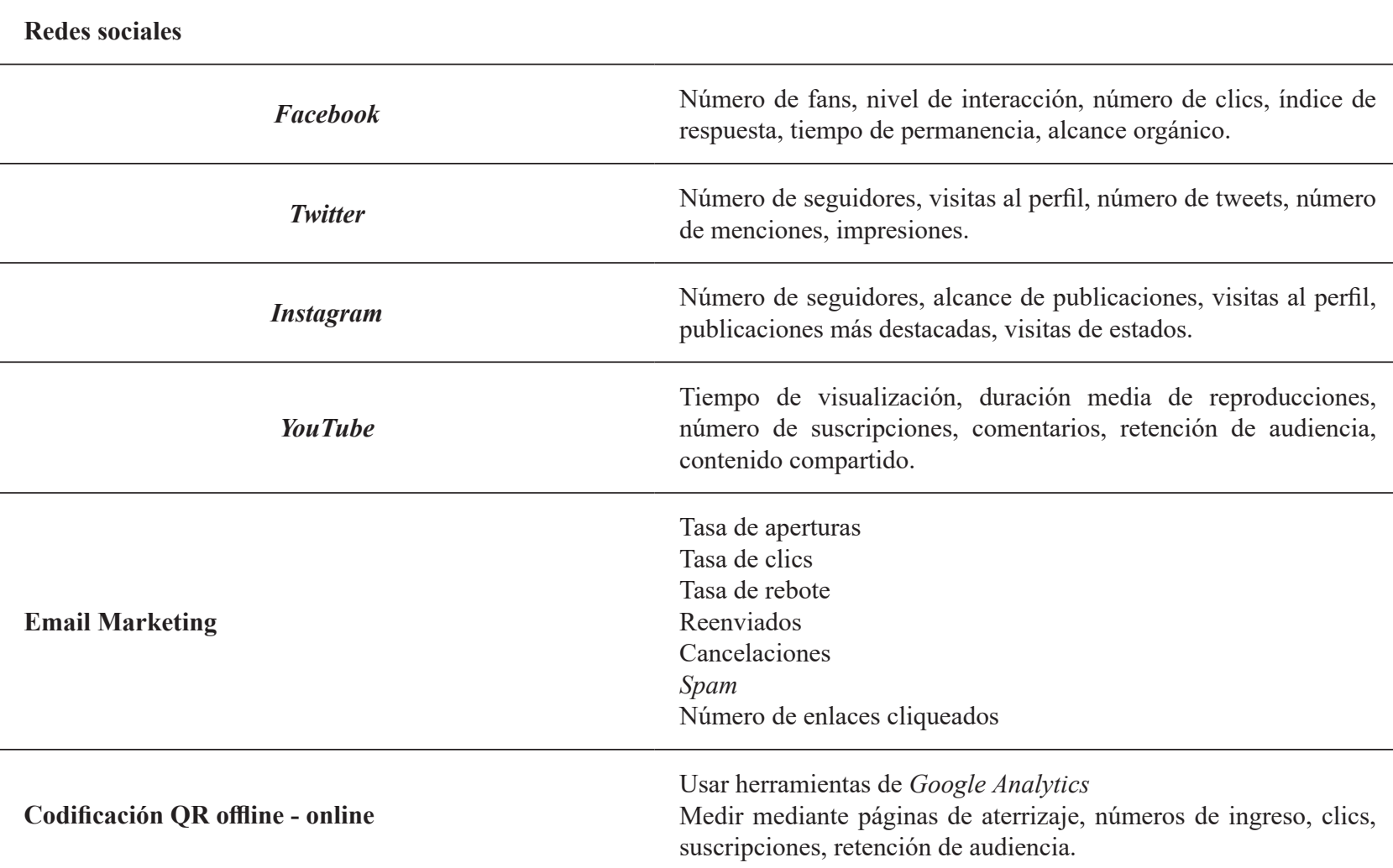

Con la lista de indicadores presentada en la tabla 5, se puede medir resultados, esto da una claridad sobre si las estrategias y tácticas están funcionando correctamente, además se puede medir por temporadas de acuerdo a los objetivos. Es recomendable tomar resultados semanales, mensuales y anuales. En el caso de las redes sociales y posicionamiento web, es posible realizar pagos por publicidad si así se lo requiere, de esta forma se obtienen resultados en un tiempo más corto (resultados que aparecen por lo general como anuncios en los motores de búsqueda) y que incluso se podría pagar para obtener un mayor alcance, es muy necesario en 
campañas en las que queremos que llegue a un público específico en un corto tiempo, que el esperar por resultados "orgánicos" (resultados que se convierten a largo plazo y que aparecen y se posicionan de forma natural sin la necesidad de ser influenciados por la publicidad de pago) estos pueden posicionarse según su relevancia en cuanto al término de búsqueda.

Como aporte adicional las campañas de comercio electrónico que van a la par con el marketing digital como los códigos QR son excelentes para campañas turísticas en aeropuertos, estaciones informativas, parques, estaciones de servicios, en la que, siendo un método offline, llega a convertirse en una idea de marketing digital que sí funciona; direccionando a los usuarios a visitar la página web de turismo, o con alguna campaña informativa mediante páginas de aterrizaje o 'landing pages' recibir suscritos e ir construyendo una base de datos de personas que están interesadas en lo que se va promocionando.

\subsection{Propuesta de página web (prototipo)}

La propuesta de página web tan solo es un prototipo -modelo básico- para ser manejado por la entidad a cargo. La estructura de la página web se diseñó a partir de los diferentes puntos de vista y requerimientos de los entrevistados, su dominio se lo escogió mediante una prueba para determinar disponibilidad a nivel mundial (visitloja.com), por ende, contó con lo siguiente:

- $\quad$ Redes sociales

- Mapas de ubicación

- Información general de los diferentes destinos que ofrece

- Directorio de planta turística y atractivos turísticos

- Galería de imágenes

- $\quad$ Servicio de correo (contacto)

- Acceso con links para cada página web de la planta turística

- Videos turísticos de Loja y sitios de interés

- Noticias y eventos actualizados

- Elección de idiomas

- Información en tiempo real

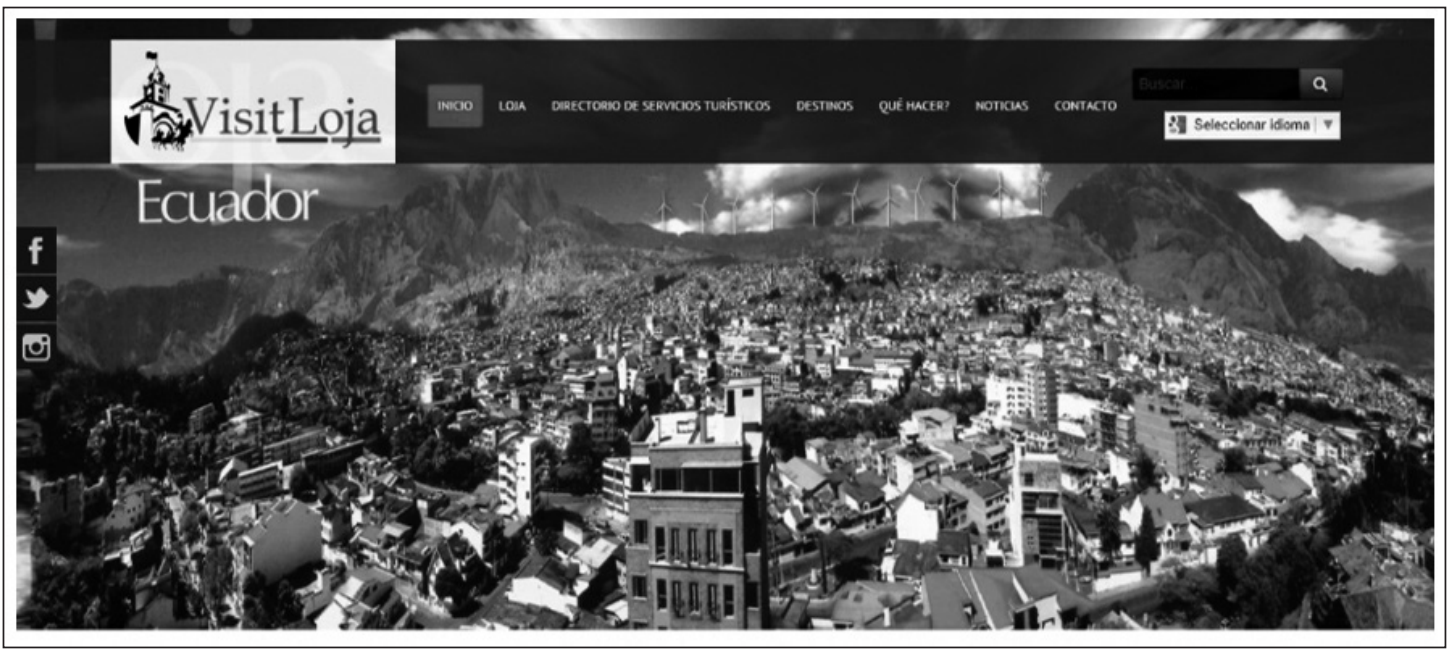

Figura 17. Página de inicio.

En la figura 17 se observa las características de la página web, con su isotipo "La Puerta de la Ciudad" que es un ícono de la ciudad de Loja y los colores de su bandera. Además, se encuentran las diferentes opciones en el menú como la página de directorio de planta turística, destinos lojanos, qué actividades se pueden realizar, atractivos turísticos, botón de idiomas y contacto. $\mathrm{Y}$ en la figura 18 se puede observar el despliegue de información de directorio (con enlaces web) y contenido de cada una de las parroquias. 

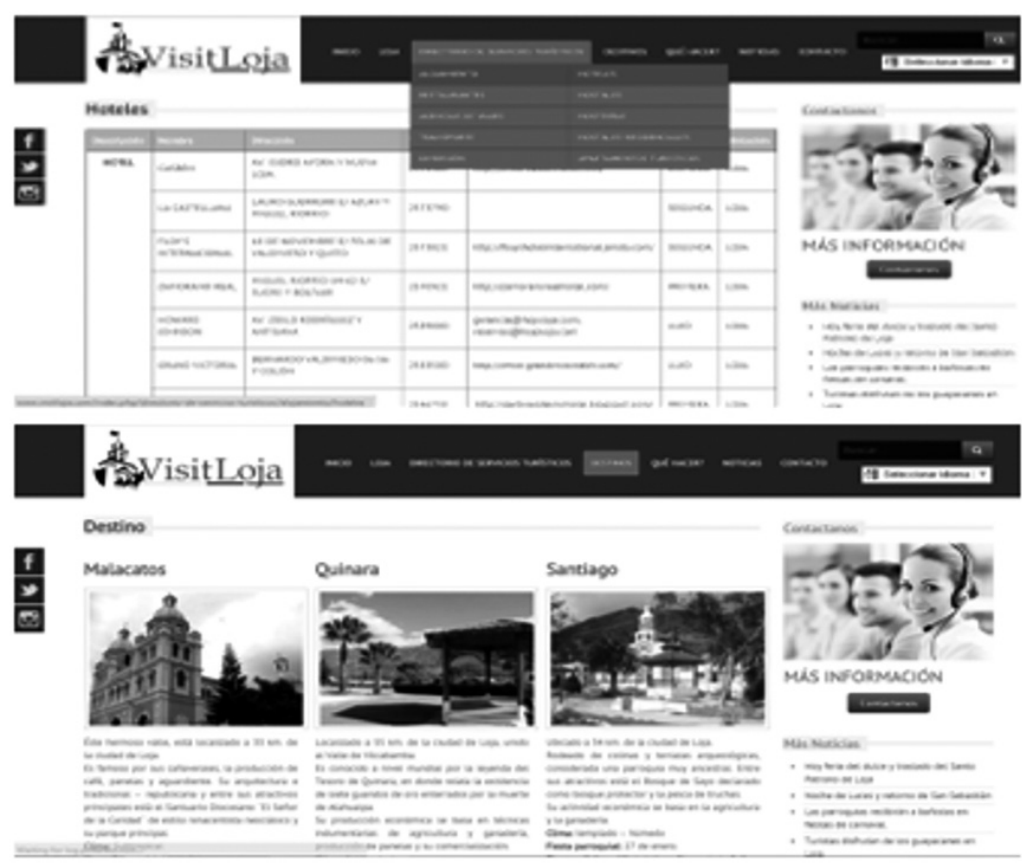

Figura 18. Aspectos del contenido.

\section{Conclusiones}

1. Necesidades: El estudio demostró que es necesario para el cantón Loja contar con un medio web oficial de turismo, considerando que las encuestas detallaron las necesidades del turista en la búsqueda de información, el tipo de información que les gustaría encontrar y la forma en cómo lograron saber de Loja. Sumado a esto, los actores entrevistados estuvieron de acuerdo en que es una oportunidad para ofertar los potenciales turísticos e incentivar a los GADs a trabajar en conjunto para brindar la mejor atención posible a quienes visitan el cantón y por qué no a la provincia. Se sugirió implementar un espacio para bolsa de empleos netamente en el sector turístico. Un aspecto importante a considerar es que debería una persona encargarse del manejo de cuentas de los medios web para un riguroso control del funcionamiento, administración y de la actualización de información.

2. Innovación y marketing digital: Se reitera que es indispensable el uso de marketing digital para promocionar un destino turístico. El marketing digital ayuda al usuario (turista) en la búsqueda de información y también a la empresa turística a ofertar globalmente sus productos y servicios. Es importante que se realice un plan de marketing enfocándolo en las metas que se quieren cumplir. Se empieza por un previo análisis situacional, se plantean objetivos (SMART) a corto, mediano y largo plazo, se proponen estrategias y tácticas, se plantea el monto de inversión, luego se efectúa un análisis de estos resultados y planes de acción, actualizando los contenidos para no perder audiencia. Además de las estrategias digitales para posicionamiento en buscadores, se debe invertir en publicidad en las redes sociales y, así mismo, proponerse objetivos para aumentar el número de seguidores, que se logre compartir contenido, y que genere una tasa de retorno positiva.

3. Finalmente, las consideraciones expuestas en este artículo ayudaron a divisar de mejor manera la situación turística del cantón Loja. Si bien es cierto en estos últimos años se ha organizado el Festival Internacional de Artes Vivas en Loja, que cuenta con un sitio web exclusivo, manejado por el Ministerio de Cultura y Patrimonio, el cual atrae a cientos de personas de todas partes del mundo, este solo se da en una fecha específica del año. Por tal motivo, el hecho de contar con sitios de información web de turismo, ayudará a que el resto del año exista información de calidad y a la mano, lista para mejorar la experiencia turística y potenciar aún más sus atractivos y, sobre todo, lograr la interacción del turista. Así también, el cantón Loja cuenta con un identificativo online que se da a conocer a nivel mundial.

Es de suma importancia contar con el catastro de establecimientos turísticos actualizado, de 
esta manera se puede ofrecer al público información necesaria sobre la planta turística y los atractivos turísticos registrados con los que cuenta el cantón Loja.

\section{Referencias}

Bernal, C. (2010). Metodología de la investigación. Administración, economía, humanidades, y ciencias sociales. Tercera Edición, México, D.F.: Pearson.

Boullón, R. (2004). Planificación del espacio turístico. El sistema turístico. México: Editorial Trillas.

Flamarich, M. (2013). Turismo, innovación, humanidades. Nuevos horizontes en la gestión del turismo. Universidad Autónoma de Barcelona, Escola Universitaria de Turisme i Direcció Hotelera de la UAB

Hernández, R., Fernández, C., \& Baptista, P. (2006). Metodología de la investigación. Cuarta edición. México, D.F.: Mc Graw Hill.

Kotler, P., García, J., Flores, J., Bowen, J., \& Makens, J. (2011). Marketing turístico. Quinta edición. Madrid, España: Pearson Education.

Kvale, S. 2011. Las entrevistas de investigación cualitativa. Editorial Morata

Municipio de Loja. (s.f.). Municipio de Loja. Consultado 09 de diciembre, 2015., Obtenido de: https://www.loja.gob.ec/

Ojeda, S. \& Gontero, S. (2010). La verdad de los estudios de opinión pública. Revista. La Sociología en sus escenarios. Medellín, Colombia: Centro de Estudios de Opinión. Universidad de Antioquia.

Organización Mundial de Turismo [OMT]. (2014). Turismo y nuevas tecnologías, Seminario Técnico. Madrid, España: Seminario San José-Costa Rica.

Organización Mundial del Turismo [OMT] (2018). El turismo y la transformación digital. Consultado 09 de noviembre, 2018. Obtenido de: http://www2.unwto.org/es/content/dmt-2018pais-anfitrion

GAD de Loja. (2013). Plan de desarrollo y ordenamiento territorial [PDOT] del cantón Loja. (2014 -2022). GAD de Loja.

Selman, H. (2017). Marketing digital. California: Editorial Ibukku.

Trespalacios, J.; Vázquez, R., \& Bello, L. (2005). Investigación de mercados. Madrid, España: Paraninfo.Rum volore con ne moluptur, explita tatur? 